\title{
Oficinas com Usuários de Saúde Mental: a Família como Tema de Reflexão
}

\author{
Raquel Souza Coelho \\ Thelma Maria Grisi Velôso \\ Universidade Estadual da Paraíba, PB, Brasil. \\ Universidade Estadual da Paraíba, PB, Brasil. \\ Sibelle Maria Martins de Barros \\ Universidade Estadual da Paraíba, PB, Brasil.
}

Resumo: Com o advento da Reforma Psiquiátrica, as ações em saúde visam promover a autonomia e o protagonismo dos usuários, a partir de uma visão integral de sujeito, em que se consideram os diferentes contextos e os grupos sociais de que ele faz parte, incluindo a família. Tal mudança paradigmática contribuiu para o abandono da perspectiva individual na assistência à saúde mental e ampliou o olhar e as ações dos profissionais para os grupos familiares. As problemáticas trazidas por diferentes usuários passam a ser compreendidas com uma visão psicossocial, em que se focalizam as relações interpessoais e familiares. Nesse contexto, este artigo relata uma experiência com um grupo de usuários de um Centro de Atenção Psicossocial (CAPS III) da cidade de Campina Grande-Paraíba, com base na Psicologia Social Comunitária. As intervenções psicossociais tinham o objetivo de promover o protagonismo dos usuários e sua corresponsabilização nos processos familiares, por meio de oficinas semanais sobre temas relacionados à família. Constatou-se que o conceito de família romântica e idealizada ainda faz parte do imaginário desses usuários. Os conflitos familiares foram destacados assim como a importância do diálogo, da reflexão e de outras estratégias para resolver problemas, o que denota posturas mais participativas e críticas. Essa experiência confirmou a relevância do desenvolvimento de ações nos serviços de atenção em saúde mental, focadas tanto na família quanto no usuário, atentos à desconstrução dos modelos de vitimização e culpabilização.

Palavras-chave: Intervenção Psicossocial; Reforma Psiquiátrica; Família; Psicologia Social Comunitária. 


\title{
Workshops with Mental Health Users: the Family as a Theme for Reflection
}

\begin{abstract}
After the approval of the Psychiatric Reform, Health actions aim at encouraging the autonomy and the central role of users, based on the whole view of the subject, taking into account the different contexts and social groups he or she is part of, including the family group. This change of paradigm has contributed to the discarding of the individual perspective in the assistance to mental health and has amplified the vision and the actions of the professionals in relation to the family groups. The problems brought to light by different users started being understood from a psychosocial perspective, on which interpersonal and family relations are focused. In this context, this article gives account of a particular experience with a group of users of a Center of Psychosocial Attention (CAPS III) in the city of Campina Grande -Paraíba, based on Social Community Psychology. The psychosocial interventions aimed at promoting the central role of users and their co-responsibility in the family processes. Weekly workshops were held about themes connected with family issues. The conclusion reached was that the concept of the romantic, idealized family still prevails among these users' imaginary. Family conflicts were emphasized as well as the importance of the dialogue, and the reflection and additional strategies to solve the problems, and this denotes more participative and critical attitudes. This experience confirmed the relevance of the actions in the services of attention to mental health, focused both on the family and on the user, paying attention to the deconstruction of the models of victimization and culpability.
\end{abstract}

Keywords: Psycosocial Intervention; Psychiatric Reform; Family; Social Communitary Psychology.

\section{Talleres con Usuarios de Salud Mental: la Familia como Tema de Reflexión}

Resumen: Con el advenimiento de la Reforma Psiquiátrica, las acciones en salud visan fomentar la autonomía y el protagonismo de los usuarios, a partir de una visión integral de sujeto, en que se consideran los contextos distintos y los grupos sociales del cual él o ella hacen parte, incluyendo la familia. Dicho cambio paradigmático contribuyó para el abandono de la perspectiva individual en la asistencia a la salud mental y amplió la mirada y las acciones de los profesionales hacia los grupos familiares. Las problemáticas traídas por distintos usuarios pasan a ser comprendidas con una visión psicosocial, en que se focalizan las relaciones interpersonales y familiares. En este contexto, este artículo relata una experiencia con un grupo de usuarios de un Centro de Atención Psicosocial (CAPS III) de la ciudad de Campina Grande-Paraíba, con base en la Psicología Social Comunitaria. Las intervenciones psicosociales tuvieron el objetivo de promover el protagonismo de los usuarios y su corresponsabilidad en los procesos familiares, por medio de talleres semanales sobre temas relacionados con la familia. Se constató que el concepto de familia romántica e idealizada hace parte aún del imaginario de estos usuarios. Los conflictos familiares fueron destacados , así como la importancia del diálogo, de la reflexión y otras estrategias para resolver problemas, lo que implica posturas más participativas y críticas. Esta experiencia confirmó la relevancia del desarrollo de acciones en los servicios de atención en salud mental, enfocadas tanto en la familia como en el usuario, atentos a la desconstrucción de los modelos de victimización y culpabilidad.

Palabras clave: Intervención Psicosocial; Reforma Psiquiátrica; Familia; Psicología Social Comunitaria. 


\section{Introdução}

Respaldadas por uma nova concepção de saúde e de ser humano, as novas formas de atenção à saúde mental, que surgiram com a chamada Reforma Psiquiátrica, incluíram diferentes ações e atores, com o fim de suplantar a ênfase na perspectiva individual, que alicerça o modelo biomédico e hospitalocêntrico. Recursos afetivos, representados por familiares e amigos, assim como sociais, sanitários, econômicos, culturais e religiosos, passaram a constituir a rede de atenção à saúde mental (Brasil, 2004). Nessa nova proposta, a família assumiu o papel de parceira, de corresponsável pelo tratamento da pessoa em sofrimento psíquico, pela resolutividade e efetividade do processo (Soares, \& Munari, 2007).

A proposta de participação direta da família no cotidiano dos serviços, por meio de projetos terapêuticos e ações de integração social (Brasil, 2004), destaca a importância desse grupo no que concerne ao suporte e ao incentivo ao usuário. Além disso, por meio da análise da dinâmica familiar, os profissionais podem compreender as diferentes nuances do sofrimento psíquico, direcionando adequadamente os projetos terapêuticos.

De acordo com Rosa (2011), as pesquisas sobre família e usuários com transtorno mental têm percebido a família de diferentes formas, a saber: como um recurso, no sentido de estratégia de intervenção; como um lugar de possível convivência do portador de transtorno mental; como sofredora e fragilizada, e que, portanto, precisa da ação do Estado; como sujeito da ação ou ator político, que se organiza em associações específicas e avalia os serviços, e como uma provedora de cuidados. Apesar de essas diferentes maneiras de conceber a família estarem articuladas às diversas perspectivas teórico-metodológicas dos autores, isso não significa que essas concepções devam ser excludentes, ao contrário, elas revelam as diversas possibilidades de se trabalhar com as famílias.
Nos serviços substitutivos de saúde mental, compreende-se a família como parceira e como um grupo que tem demandas e direitos próprios. Geralmente são oferecidas atividades individuais e grupais voltadas para as famílias dos usuários. Entretanto, o trabalho com o grupo familiar também acontece de outras formas, quando, por exemplo, os profissionais abordam o tema família em diferentes tipos de atendimento voltados para a pessoa em sofrimento psíquico.

Neste artigo, propomo-nos, com base numa experiência em Psicologia Social Comunitária em um Centro de Atenção Psicossocial (CAPS III), localizado em Campina Grande-PB, contribuir, a partir da perspectiva dos próprios usuários, com uma reflexão sobre o papel da família na rede intersetorial de saúde mental. Considerando a reconhecida relevância da família nos processos de saúde e doença, a depender do papel que exerce, como agente protetor ou reforçador de vulnerabilidade (Sousa, \& Baptista, 2008), realizamos oficinas ${ }^{1}$ com um grupo de usuários do serviço voltadas para reflexões acerca das relações familiares. Os conteúdos construídos nessas oficinas são aqui analisados, com o objetivo de contribuir em novas abordagens com familiares e usuários da rede de saúde mental.

Os CAPS são serviços comunitários de saúde que oferecem assistência especializada, em regime de atenção diária e ambulatorial, a usuários do serviço de saúde mental e seus familiares. Seu objetivo é de promover a cidadania e garantir os direitos dos usuários e sua reinserção social. ${ }^{2}$ No que diz respeito ao funcionamento do CAPS III de Campina Grande, algumas etapas são seguidas. Ao chegarem ao CAPS, os usuários passam por um acolhimento que, conforme orientação do Ministério da Saúde (Brasil, 2004), tem como objetivos principais compreender a situação da pessoa da forma mais abrangente possível e começar a estabelecer um vínculo terapêutico e de confiança entre a pessoa e os profissionais do serviço. $\mathrm{O}$ estabe-

\footnotetext{
${ }^{1}$ As oficinas são entendidas, conforme definido por Afonso e Coutinho (2010), como um trabalho estruturado em torno de uma questão central que o grupo pretende elaborar. Independentemente da quantidade de encontros, as oficinas envolvem o sujeito integralmente e afeta formas de pensar, agir e sentir. Ela se diferencia de um projeto puramente pedagógico, por envolver vivências e significados relacionados ao tema trabalhado. Desse modo, a oficina é uma prática de intervenção psicossocial.

${ }^{2}$ Existem diferentes tipos de CAPS. Segundo o Ministério da Saúde (Brasil, 2004), o CAPS I é um serviço para cidades de pequeno porte que devem dar cobertura, durante o dia, para adultos, crianças e adolescentes com transtornos mentais severos e pessoas com problemas devido ao uso de álcool e outras drogas. Já os CAPS II são serviços para cidades de médio porte e atendem, durante o dia, à clientela adulta. Os CAPS III são serviços 24 horas, geralmente disponíveis em grandes cidades, que atendem à clientela adulta. Existem também os CAPSi que são serviços para crianças e adolescentes, em cidades de médio porte, que funcionam durante o dia. Já os CAPSad estão voltados para pessoas com problemas relacionados ao uso de álcool ou outras drogas. Geralmente disponível em cidades de médio porte, esse serviço funciona apenas durante o dia. Já o CAPS ad III funciona 24 horas.
} 
lecimento de um diagnóstico, mesmo sendo importante, não é a prioridade desse momento. Caso seja constatada a necessidade de acompanhamento, é preparado um projeto terapêutico singular, que corresponde a um conjunto de atendimentos personalizados, feitos dentro e fora da unidade e que respeitem as particularidades de cada indivíduo. Ele também define as atividades de que o usuário participa quando está no serviço. Em geral, o profissional que o acolhe se torna o seu terapeuta de referência (TR) e responsável por acompanhar o projeto terapêutico, redefinindo-o conforme necessário (Brasil, 2004). O atendimento aos usuários é feito por uma equipe multidisciplinar, composta de médicos, psicólogos, enfermeiros, assistentes sociais, pedagogos, entre outros. Essa instituição abriga cerca de 700 adultos, de ambos os sexos, portadores de transtornos mentais severos. O serviço funciona 24 horas, todos os dias da semana, e dispõe de leitos para curta permanência (cerca de duas semanas, no máximo) para usuários em crise. Diversas atividades são realizadas na instituição, entre elas, podemos citar: grupos operativos e terapêuticos; assembleias de usuários; oficinas de música, artes e outras; atendimento psicológico e psiquiátrico; escuta; atividades físicas; grupos de família; brechós; festas comemorativas e reuniões dos profissionais.

As intervenções psicossociais que realizamos no CAPS III foram respaldadas nos pressupostos da Psicologia Social Comunitária. Conforme Freitas (1996, p.73), essa área de conhecimento da Psicologia "compreende o homem como sendo sócio-historicamente construído e, ao mesmo tempo, construindo as concepções a respeito de si mesmo, dos outros homens e do contexto social". Por meio da linguagem, das relações grupais, das emoções e dos afetos característicos da subjetividade, o psicólogo comunitário atua no nível da consciência, da atividade e da identidade dos indivíduos, a favor da construção de relações comunitárias (Lane, 1996). Convém compreender que o objetivo da intervenção psicossocial é de promover melhores condições humanas e boa qualidade de vida (Sarriera, 2004). O psicólogo facilita mudanças ao fomentar práticas coletivas organizadas que possibilitam a leitura crítica da realidade e a transformação social.

A atuação referenciada pela Psicologia Social Comunitária, em diálogo com a Educação Popular (EP) em saúde, rompe com o modelo assistencialista tradicionalmente ligado aos serviços de saúde e passa a trabalhar em prol do desenvolvimento de uma reflexão crítica, estimulando a autonomia e o protagonismo social das pessoas. Em relação a isso, Alberti, Salbego, Martins e Alberti (2014) afirmam que a Educação Popular, ao reconhecer o outro como um sujeito de direitos e protagonista da própria existência, promove ações emancipatórias e dialógicas que contribuem para que ele conquiste sua autonomia.

Nossa escolha por esse referencial teórico baseou-se na crença de que a atuação da Psicologia no campo das políticas públicas requer práticas de saúde que reconheçam a importância da participação crítica e coletiva na elaboração de propostas voltadas para as necessidades dos grupos e para a transformação social. A interface da Psicologia com o campo das políticas públicas configura-se, portanto, como uma aposta em práticas sociais promotoras de novos mundos, como destaca Mancebo (2011), bem como de novas subjetividades.

A Psicologia Social Comunitária, a Educação Popular e os princípios da Reforma Psiquiátrica serviram de base para a construção e o desenvolvimento das atividades realizadas no CAPS III de Campina Grande. No entanto, neste relato, faremos referência apenas às oficinas com um grupo de usuários cuja temática trabalhada foi "a família”.

Por reconhecer a pluralidade de arranjos familiares que revelam a insuficiência de certos parâmetros que definem a família (como consanguinidade, heterossexualidade, divisão da mesma casa, entre outros), partilhamos a ideia de família como um grupo afetivo, influenciado por uma diversidade de fatores e contextos e caracterizado por relações íntimas e intergeracionais. Nesse grupo, inicia-se a aprendizagem dos afetos, dos valores e das relações sociais (Dessen, 2010; Simionato, \& Oliveira, 2003).

Como já explicitado, entendemos a família, também, como uma unidade básica de cuidado para a pessoa em sofrimento psíquico, razão por que é importante que os profissionais participem da identificação de recursos que esse grupo apresenta e de fatores de vulnerabilidade que o impedem de desempenhar sua função de cuidar ou a dificultam (Pontes, 2009). A identificação das potencialidades e das dificuldades, assim como as intervenções realizadas no campo da saúde mental devem contemplar todos os atores envolvidos nesse grupo, porque os membros familiares se influenciam mutuamente.

Este relato é relevante, pois é imprescindível não só escutar os familiares dos portadores de transtorno 
mental, mas também os usuários, e lhes dar oportunidades para que reflitam sobre seu lugar no grupo familiar e sobre o seu papel na construção de novas relações. Com o intuito de atingir esse objetivo, o tema família foi inserido nas oficinas com os usuários.

\section{Percurso metodológico}

As atividades aqui relatadas foram desenvolvidas com um grupo de usuários de saúde mental no CAPS III, como já ressaltado. O grupo reunia-se semanalmente, há cerca de um ano, numa sala da instituição e contava com a participação de quatro a 12 usuários de ambos os sexos, adultos jovens e adultos a cada oficina. Assim, a faixa etária variava de 20 a 59 anos. Todos residiam com seus familiares - pais, irmãos, cônjuges e/ou filhos. A maioria já havia sido internada em hospitais psiquiátricos e trazia em seus corpos e subjetividades as marcas da reclusão, do silêncio e das demais violências a que foram submetidos pela psiquiatria asilar.

Como prática de intervenção psicossocial, as oficinas nos permitiram trabalhar diversas temáticas com os usuários. Em determinado momento, propusemo-nos a trabalhar o tema "família", recorrente nas falas dos usuários durante as oficinas. Ao longo dos encontros, discutimos sobre o significado de família, suas características positivas e negativas e o papel dos usuários nessas relações. Tínhamos o intuito de fomentar uma reflexão sobre essas relações atentando para a sua importância e para a forma como cada um poderia contribuir para a boa qualidade delas, tendo sempre como horizonte o estímulo ao protagonismo e à autonomia dos usuários.

Inspirando-nos na proposta da Arteterapia, que sugere a utilização da arte em contextos terapêuticos, com a intenção de possibilitar a expressão, a elaboração e a reelaboração dos modos de estar, pensar e sentir o mundo (Vanderley, 2001), as linguagens artísticas foram o principal instrumento metodológico utilizado para o desenvolvimento das oficinas, com destaque para o uso dos jogos e exercícios do Teatro do Oprimido (TO) propostos por Augusto Boal.

A arte caracteriza-se como um eficiente instrumento metodológico, porquanto tem a função de criar uma consciência do mundo, não necessariamente verbal ou verbalizável (Boal, 2008). No campo da saúde mental, como discutem Tavares e Sobral (2005), a arte surge como um recurso para a proposta de humanizar a assistência. Utilizada em atividades diversas no CAPS, ela produz subjetividades, catalisa afetos e engendra meio de produção e inserção social das pessoas em sofrimento psíquico.

Por meio do Teatro do Oprimido, podem-se questionar dogmas ou regras fixas adotadas pelas pessoas de forma mecânica. Com o trabalho em grupo, é possível compreender as condições objetivas de produção dessas ideias arraigadas socialmente e adotadas sem questionamentos. Através dos exercícios, os sujeitos podem refletir sobre si mesmos, já que visam a um melhor conhecimento do corpo, suas atrofias e hipertrofias, mecanismos, capacidades de recuperação, reestruturação e rearmonização. Os jogos, por sua vez, trabalham a expressividade dos corpos como emissores e receptores de mensagens (Boal, 2008).

\section{Relato da experiência}

Neste artigo, tratamos das oficinas realizadas sobre a temática "família", das quais escolhemos três. Considerando que é importante salvaguardar o anonimato dos usuários, utilizamos nomes de cores para identificar cada um. A ideia é de relatar sinteticamente como ocorreu cada uma dessas oficinas, para, no próximo item, fazer algumas considerações teóricas. Cabe destacar, ainda, que estamos fazendo um pequeno recorte de uma experiência muito mais ampla.

\section{Oficina: "Significados sobre família"}

Participaram dessa oficina oito usuários. Como sempre fazíamos, iniciamos com uma técnica de relaxamento, que consistia em respirar profundamente, alongar cada parte do corpo e concentrar-se na oficina que se iniciava. Com o objetivo de introduzir a temática e fomentar discussões, iniciamos a intervenção com o exercício de Teatro do Oprimido (TO), intitulado "Imagem da palavra" que, conforme Boal (2002, p.18), caracteriza-se da seguinte forma: o diretor convida voluntários para que mostrem, de forma visual, o tema escolhido (pelo grupo). Cada um trabalha sem olhar o que fazem os demais, para que não haja influências. Cada um vai ao centro e, usando somente o corpo expressa o tema.

O exercício consistiu em expressar, por meio de gestos e movimentos, a imagem que os usuários construíam do termo indutor "família”. Esperávamos que esse exercício gerasse diálogos sobre a definição de família socialmente construída e sobre a família dos participantes. Como não pudemos evitar que os usuários trabalhassem sem olhar uns para os outros, 
todos eles fizeram corações com as mãos e disseram que aquilo representava a união e o amor da família.

Em seguida, passamos para a atividade de desenho. Cada participante desenhou o que entendia por família; depois, conversamos sobre os desenhos e sobre as famílias deles. Os usuários disseram que havia coisas ruins na família, mas também identificaram coisas boas. $\mathrm{O}$ amor, a união e o companheirismo eram características da família, no entanto, estavam faltando nas famílias dos usuários. Vermelho, por exemplo, além de desenhar pessoas de mãos dadas e uma casa, que entendia como o alicerce da família, escreveu: "Família é união, companheirismo, amor, fraternidade". Desejando mais união familiar, ele ressaltou a falta que os pais faziam e a separação da família após a morte deles. Lilás e Amarelo frequentemente relatavam os conflitos que tinham em casa e afirmaram que era necessário haver mais união e paz na família. Verde, por sua vez, falou que havia coisas boas na família, mas que, na sua, faltava amor entre os pais, fato que ele retratou no desenho que fez de um homem, uma mulher e um coração. Porém, o coração estava afastado do casal, que parecia não se tocar nem se olhar.

Por fim, iniciamos uma reflexão sobre as características das famílias, com o intuito de desconstruir o ideal de família "perfeita", porque cada uma delas tem suas limitações. É necessário pensar em modos de intervenção que revertam a lógica de idealização e culpabilização da família (Severo, Dimenstein, Brito, Cabral, \& Alverga, 2009). A oficina foi encerrada como sempre fazíamos, com um "Círculo de Energia", que consistia em, organizados em círculo e de mãos dadas, recapitular as principais questões discutidas na oficina. Nesse momento, relembramos aspectos importantes da que foi realizada naquele dia, em que obtivemos informações sobre as famílias dos usuários e sobre alguns sentimentos e representações deles acerca de seu grupo familiar.

\section{Oficina: "O que gosto e o que não gosto na família"}

Nessa oficina, contamos com a participação de doze usuários. Iniciamos o encontro com a técnica de relaxamento e, em seguida, continuamos a reflexão sobre o tema família. Para essa oficina, selecionamos uma música intitulada "Família", da banda Titãs. A música, como instrumento metodológico, propicia a expressão de sentimentos e emoções e contribui para que sejam pensados e discutidos (Araújo, 1999).
A música, ao criar e despertar a subjetividade, parece modificar a maneira como a pessoa dá significado ao mundo que a rodeia (Maheirie, 2003).

No momento reservado para o debate, foram produzidos novos discursos com a introdução de novos elementos. Os participantes referiram que os animais também fazem parte da família, como a música dizia. Alguns falaram sobre seus aspectos problemáticos, como a falta de união, as brigas, as discussões. Outros destacaram os aspectos positivos, que "é bom ter uma família", e a importância de que haja união no grupo familiar.

Posteriormente, propusemos uma atividade de colagem, para que os usuários expressassem, por meio de figuras, coisas de que gostavam e de que não gostavam na família. Após a colagem das figuras, iniciamos uma discussão sobre tais produções. Vermelho relatou que o de que mais gostava em sua família era o filho; e a falta de união, o de que não gostava. Vários outros usuários também apontaram a falta de união da família. Foi abordada também a questão do alcoolismo. Marrom, por exemplo, que era alcoolista, assim como sua mãe, não mencionou o que mais lhe desagradava na família, mas que não gostava da bebida e que ela prejudicava a família.

Já Azul escolheu figuras de malas para representar os irmãos e afirmou que só precisava da mãe, pois não gostava dos familiares. Vários usuários, como Laranja, falaram que o de que gostam na família são os sobrinhos. Laranja também foi o único participante que disse não saber o que não gostava na própria família. Outros falaram sobre os pais, e alguns destacaram a falta que sentem dos pais falecidos.

Depois de ter sido identificada a demanda do grupo, perguntamos-lhes o que achavam que poderiam fazer para mudar o que não gostam na família. Partimos do pressuposto de que os serviços de atenção à saúde mental precisam abandonar as práticas excludentes e tutelares e trabalhar em prol do protagonismo e da autonomia dos usuários (Medeiros, \& Guimarães, 2002). Nesse sentido, procuramos estimular a ideia de que eles também são responsáveis e podem contribuir para melhorar o relacionamento familiar com uma postura mais ativa e participativa.

Os usuários propuseram estratégias como 'dialogar' e 'conversar', para tentar resolver os problemas sem gerar mais conflitos e 'pensar' antes de agir ou falar. Chamou-nos a atenção o fato de alguns deles não defenderem estratégias relacionadas à interação com a família, mas a uma maior separação, como no discurso 
de Azul, que já havia dito antes que não gostava da família. Nessa oficina, também encerrada com o Círculo de Energia, cada um refletiu sobre a realidade de sua família. Também enfatizamos a responsabilização dos usuários na relação com os seus familiares.

\section{Oficina: "Lembranças"}

Tendo em vista os relatos sobre conflitos familiares em oficinas anteriores, nossa proposta, nesse encontro, foi de resgatar lembranças de bons momentos que fortalecessem os vínculos familiares e contribuíssem para melhorar os relacionamentos. Essa oficina contou com a presença de seis usuários e começou com o relaxamento. Em seguida, utilizando imagens mentais como recurso, propusemos que os usuários 'viajassem' em sua imaginação até o passado e relembrassem um momento feliz que vivenciaram com a família - uma adaptação do exercício de TO "Memória e emoção: lembrando um dia do passado". Conforme Boal (2008), nesse exercício, cada participante escolhe algum dia do seu passado em que algo importante ou marcante tenha acontecido e que ainda hoje provoque uma emoção e conta para outro participante, chamado de copiloto. Como esse exercício foi adaptado, não houve copilotos.

$\mathrm{Na}$ sequência, dividimos os participantes em dois grupos e entregamos-lhes uma tigela, onde colocamos farinha de trigo, água e anilina para produzir massa de modelar, que eles deveriam utilizar para representar o que tinham relembrado. A seguir, cada um deles apresentou sua produção, algumas das quais descreveremos a seguir.

Vermelho fez uma panelinha de barro, para representar uma feijoada em família, realizada quando seu irmão foi promovido no emprego. Azul fez um boneco, representando um cantor que o faz lembrar coisas boas da infância. Entretanto, durante a discussão, ele não relatou bons momentos com sua família. Amarelo fez um bolo, que simbolizava uma festa de aniversário da infância que fora um momento especial para ele. Lilás fez uma tapioca. Primeiramente, ela não fez referência a alguma lembrança, mas, depois, afirmou que gostava muito da mãe, embora a mãe não gostasse dela.

Em seguida, refletimos sobre as esculturas feitas com a massa de modelar e conversamos a respeito do que poderíamos fazer para que os momentos bons se repetissem. Os usuários falaram novamente sobre a necessidade de mais união na família, mais amor, a importância de ter paciência, evitar brigas e discussões. Nesse diálogo em grupo, continuamos a estimular a compreensão de que eles também são responsáveis pelo que acontece em suas famílias e que, portanto, podem intervir ativamente e criticamente nessas relações. Como de costume, a oficina se encerrou com o Círculo de Energia.

\section{Algumas considerações teóricas}

Guiando-nos pela perspectiva teórico-metodológica da Psicologia Social Comunitária, através dessas oficinas, promovemos um debate sobre as relações familiares, o qual foi aprofundado em outras oficinas e contribuiu para incrementar a reflexão crítica e o protagonismo social desse grupo. Com isso, estimulamos a ideia de que os usuários podem exercer sua autonomia também na família e colaborar para a melhoria das relações.

Em nossas oficinas, os participantes enfatizaram, sobretudo, a importância da união e do amor na família. Embora tenham incluído os animais como membros da família, rompendo o tradicional discurso normatizador e dando indícios de transformações na forma de dar significado à família, seus discursos parecem estar ancorados em uma ideia romântica e idealista de família que caracterizou o modelo nuclear moderno. Seguindo essa lógica de pensamento, a família não deve ter conflitos, porque deve ser um grupo harmônico.

A família nuclear burguesa assumiu o lugar de modelo ideal de família, e isso, frequentemente, gera sentimentos negativos de inadequação nas pessoas que não têm um grupo familiar correspondente a esse ideal (Szymanski, 2004). Percebemos isso nos discursos dos usuários e podemos sugerir que esse ideal de família também origina expectativas inalcançáveis e, posteriormente, causa frustração e mais sofrimento psíquico por não ser concretizado. $\mathrm{O}$ fato de as próprias famílias não corresponderem ao que os usuários esperam, ou acreditam ser o ideal, acaba por provocar mais sofrimento. A família é produzida socialmente, em determinado tempo histórico, e marcada por contradições e conflitos específicos. Concordamos com os autores acima citados quando ressaltam a necessidade de se desconstruir esse modelo de família, com o intuito de legitimar outras configurações familiares. A promoção de novos significados em torno da família pode proporcionar uma leitura crítica e realista desse grupo social que considere a existência de conflitos advindos de seu ciclo de vida, de seu contexto ou de eventos inesperados. 
Por outro lado, podemos compreender que o desejo de união, mesmo sendo expresso de forma idealizada, pode estar revelando o fato de alguns usuários se sentirem desamparados. Borba, Schwartz e Kantorski (2008) apontam que as relações afetivas na família podem ser prejudicadas pela sobrecarga (financeira, física, do cuidado e emocional) que surge da vivência do sofrimento psíquico. Assim, os profissionais devem estar atentos aos fatores que causam essa sobrecarga e à qualidade dos relacionamentos estabelecidos entre as pessoas em sofrimento psíquico e suas famílias.

Outra possibilidade de análise seria reconhecer que essas famílias têm conflitos, de certa forma, difíceis para os usuários. As constantes referências à existência de brigas, discussões e falta de união indicam que há problemas de relacionamento dentro das famílias, o que pode ser também alimentado pela sobrecarga familiar acima mencionada. Entretanto, não podemos ter uma visão simplista, em que se culpa o usuário pelos conflitos familiares, tampouco culpabilizar a família pela emergência do sofrimento psíquico e desconsiderar a influência de outros fatores em jogo, como os sociais e os econômicos. Os conflitos, de todo modo, influenciam a vida das pessoas em sofrimento psíquico e são merecedores de atenção. Consideramos que, ao promover uma reflexão sobre essas questões, estimulamos também a participação ativa dos usuários na melhoria dessas relações.

A falta de lembrança de bons momentos com a família, por parte de Azul e de outros usuários, possivelmente relaciona-se a momentos em família e a sentimentos daí decorrentes que são difíceis de ser expressos. Em relação a isso, Farias et al. (2016) ressaltam que essas atividades de atenção psicossocial, muitas vezes, são o primeiro lugar onde aquele usuário terá liberdade de se expressar sem ser estigmatizado. Desse modo, o usuário pode, no começo, ter certa dificuldade de expressar seus sentimentos, e o profissional deve estar atento a isso, propiciando o contexto adequado e ouvindo o que é dito de forma verbal e não verbal.

Em alguns momentos da intervenção, verificamos a construção da solidariedade entre os membros do grupo, ao compartilharem ideias, posicionamentos e sentimentos. Esse processo vai ao encontro do paradigma da desinstitucionalização, que privilegia a promoção de dispositivos grupais e tem como preocupação a solidariedade na atenção à clientela de cuidado contínuo (Vasconcelos, 2004).
A escolha dos participantes por estratégias como o diálogo e a reflexão para resolver conflitos familiares revela o deslocamento de um papel passivo para o de protagonista, que busca reconstruir os laços de família ou melhorar sua qualidade. O desejo de se distanciar, de se isolar ou de "delimitar território", citado por outros participantes, pode auxiliar no processo de busca de autonomia do usuário em relação a sua família que, por vezes, não respeita seu espaço.

Como discutem Pereira e Pereira Junior (2003), muitos usuários convivem com o estigma, o desprezo, o desrespeito e a desconfiança das próprias famílias, e isso acarreta prejuízos nos relacionamentos e em sua subjetividade. Rosa (2011) fortalece essa discussão ao afirmar que a infantilização, decorrente da superproteção, pode ocorrer em certos grupos familiares. Ao afirmar seu desejo de se "isolar" e "delimitar território", esses usuários podem estar procurando romper com essa infantilização. A família se organiza como pode para cuidar da pessoa em sofrimento psíquico, mas, nem sempre, as estratégias empregadas são eficientes ou beneficiam o grupo familiar. Assim, é necessário colaborar para a criação de estratégias de cuidado tanto para a família quanto para o usuário.

$\mathrm{O}$ incentivo à rememoração de lembranças positivas na família, estimulado em uma das oficinas, teve como objetivo instaurar um processo de reelaboração de experiências catastróficas e de dar um novo sentido aos eventos (Vasconcelos, 2007). Ao levar para a memória essas lembranças, os usuários tiveram a oportunidade de reavaliar situações, algumas não tão distantes, como a feijoada, pelo novo emprego do irmão e outras vindas de muitos anos atrás, ainda na infância. Por meio do dispositivo grupal, outros sentidos e sentimentos em relação à família foram provocados, com o fim de motivá-los a pôr em prática as estratégias discutidas em encontro anterior e estimular o protagonismo dos usuários em relação as suas famílias. Com o trabalho em grupo, podem-se construir novos modos de existir, por meio de processos de criação de si e do mundo (Passos, 2007).

Nas oficinas ministradas, percebemos também a necessidade de ultrapassar propostas de atuação baseadas em modelos clínicos tradicionais e de compreendermos a necessidade de refletir sobre as condições socioeconômicas e culturais que influenciam o nosso contexto de atuação e a vida dos indivíduos com os quais trabalhamos. Em cada oficina, adentramos um pouco mais o universo de cada usuário e trouxemos à tona novas questões sobre as condições 
de vida deles. Esses aspectos são extremamente relevantes, como alertam Sales e Dimenstein (2009).

Aprendemos que lidar com a família, como uma unidade de cuidado, realmente requer o conhecimento de suas singularidades e da complexidade de fatores envolvidos, como afirmam Severo, Dimenstein, Brito, Cabral e Alverga (2007), e que olhemos "para a família que sofre, e não, para a família de risco ou incapaz" (Sawaia, 2003, p. 45) e potencializemos os membros, nesse caso, os usuários, para ressignificar o sofrimento e reconstruir suas narrativas.

\section{Considerações finais}

Por meio das intervenções realizadas no CAPS III, procuramos trazer algumas contribuições com o intuito de fomentar a discussão sobre a importância dos processos familiares na rede intersetorial em saúde mental.

Todas as oficinas que facilitamos com o grupo de usuários tiveram o objetivo de estimular a autonomia, o protagonismo social e a reflexão crítica desse grupo, como propõe a Psicologia Social Comunitária. As oficinas realizadas sobre o tema "família" contribuíram para que os usuários fizessem algumas reflexões, desejassem participar das relações familiares mais ativamente e tivessem mais responsabilidades. Considerando que o fortalecimento dos laços familiares é condição para se concretizar a proposta da rede de atenção em saúde mental, nossa intenção era de que essas ações fossem condizentes com tais princípios. Concepções de família, aspectos positivos e negativos observados pelos usuários e atitudes que podem colaborar para melhorar as relações foram alguns dos temas debatidos. Percebemos a existência de sentimentos tanto positivos quanto negativos, associados às relações familiares. Consideramos que atingimos o objetivo de iniciar um processo de reflexão sobre as relações familiares e o papel dos usuários nesses relacionamentos.

Futuros encaminhamentos podem incluir o desenvolvimento de ações em longo prazo e a avaliação de possíveis impactos que a participação nessas ações poderá ter nas relações familiares dos usuários. Acreditamos que experiências como esta, com o tempo, podem, efetivamente, modificar as relações familiares. Isso poderia ser acompanhado e avaliado através dos conteúdos trazidos pelos próprios usuários participantes e dos relatos dos familiares.

Também ressaltamos a importância de haver intervenções com a participação do usuário e de seus familiares. Os recursos teóricos e metodológicos da Terapia Familiar, por exemplo, poderiam subsidiar algumas ações em saúde mental. Nesse caso, os diferentes modelos das intervenções familiares devem ser adaptados aos objetivos sociais característicos da intervenção psicossocial. Além disso, destacamos intervenções que levem em conta a rede pessoal significativa, com o intuito de dar suporte às famílias e aos usuários em sofrimento psíquico.

Com base em nossa experiência, podemos afirmar que, para efetivar a proposta da Reforma, é importante desenvolver ações por meio das quais possamos discutir sobre as relações familiares em grupos com as famílias, com os usuários e com os usuários e seus familiares, a partir de uma perspectiva que estimule seu protagonismo, sua autonomia e corresponsabilização, a fim de que possam abandonar as tradicionais posições de vítimas e de culpados.

\section{Referências}

Afonso, M. L., \& Coutinho, A. R. A. (2010). Metodologias de trabalho com grupos e sua utilização na área da saúde. In M. L. Afonso.(Org), Oficinas em dinâmica de grupo na área da saúde (pp. 59-84). São Paulo, SP: Casa do Psicólogo.

Alberti, G. F., Salbego, C. C., Martins, S. O. R., \& Alberti, D. L. (2014). Educação popular trabalhada em oficinas de saúde: a sexualidade durante o adolescer. Revista de Educação Popular, 13(1), 75-81. Recuperado de http://www. seer.ufu.br/index.php/reveducpop/article/view/24871

Araújo, R. C.. (1999). A música como instrumento da Psicologia Comunitária. In I. R. Brandão \& Z. A. C. Bonfim (Orgs.), Os jardins da psicologia comunitária: escritos sobre a trajetória de um modelo teórico-vivencial (pp.121-129). Fortaleza, CE: Universidade Federal do Ceará.

Boal, A. (2008). Jogos para atores e não atores (12a ed.). Rio de Janeiro, RJ: Civilização Brasileira.

Boal, A. (2002). Teatro do Oprimido de ponto a ponto. Rio de Janeiro, RJ: Centro de Teatro do Oprimido.

Borba, L. O., Schwartz, E., \& Kantorski, L. P. (2008). A sobrecarga da família que convive com a realidade do transtorno mental. Acta Paulista de Enfermagem, 21(4), 588-594. https://doi.org/10.1590/S0103-21002008000400009 
Psicologia: Ciência e Profissão Abr/Jun. 2017 v. 37 n², 489-499.

Brasil. (2004). Ministério da Saúde. Saúde mental no SUS: os centros de atenção psicossocial. Brasília, DF: o autor.

Dessen, M. A. (2010). Estudando a família em desenvolvimento: desafios conceituais e teóricos. Psicologia: Ciência e Profissão, 30(spe), 202-219. https://doi.org/10.1590/S1414-98932010000500010

Farias, I. Z., Thofehrn, M. B., Andrade, A. P. M., Carvalho, L. A., Fernandes, H. N., \& Porto, A. R. (2016). Oficina terapêutica como expressão da subjetividade. SMAD, Rev. Eletrônica Saúde Mental Álcool Drog., 12(3), 147-53. https://doi.org/10.11606/issn.1806-6976.v12i3p147-153

Freitas, M. F. Q. (1996). Psicologia na comunidade, Psicologia da comunidade e Psicologia (social) comunitária: práticas da psicologia em comunidade nas décadas de 60 a 90 no Brasil. In R. H. F. Campos (Org.), Psicologia social comunitária: da solidariedade à autonomia (pp. 54-79). Petrópolis, RJ: Vozes.

Lane, S. T. M. (1996). História e fundamentos da psicologia comunitária no Brasil. In R. H. F. Campos (Org.), Psicologia social comunitária: da solidariedade à autonomia (pp. 17- 34). Petrópolis, RJ: Vozes.

Maheirie, K. (2003). Processo de criação no fazer musical: uma objetivação da subjetividade, a partir dos trabalhos de Sartre e Vygotsky. Psicologia em Estudo, 8(2), 147-153. https://doi.org/10.1590/S1413-73722003000200016

Mancebo, D. (2011). Prefácio. In M. G. M. Gonçalves (Org.), Psicologia, subjetividade e políticas públicas (pp.11-15). São Paulo, SP: Cortez.

Medeiros, S. M., \& Guimarães, J. (2002). Cidadania e saúde mental no Brasil: contribuição ao debate. Ciência \& Saúde Coletiva, 7(3) 571-579. https://doi.org/10.1590/S1413-81232002000300014

Passos, E. (2007). Quando um grupo é a afirmação de um paradoxo. In R. B. Barros (Org.), Grupo: a afirmação de um simulacro (pp.11-19). Porto Alegre, RS: Sulina.

Pereira, M. A. O., \& Pereira Junior, A. (2003). Transtorno mental: dificuldades enfrentadas pela família. Revista da Escola de Enfermagem USP, 37(4), 92-100. https://doi.org/10.1590/S0080-62342003000400011

Pontes, M. N. (2009). Famílias e psicoses. In L. C. Osório, \& M. E. P. Valle (Orgs.), Manual de terapia familiar (pp. 343-349). Porto Alegre, RS: Artmed.

Rosa, L. (2011). Transtorno mental e o cuidado na família. São Paulo, SP: Cortez.

Sales, A. L. L. F., \& Dimenstein, M. (2009). Psicólogos no processo de reforma psiquiátrica: práticas em desconstrução? Psicologia em Estudo, 14(2), 277-285. https://doi.org/10.1590/S1413-73722009000200008

Sarriera, J. C.. (2004). Intervenção psicossocial e algumas questões éticas e técnicas. In J. C. Sarriera (Org.), Psicologia comunitária: estudos atuais (pp. 19-41). Porto Alegre, RS: Sulina.

Sawaia, B. B. (2003). Família e afetividade: a configuração de uma práxis ético-política, perigos e oportunidades. In A. R. Acosta \& M. A. F. Vitale. (Orgs), Família: redes, laços e políticas públicas (pp. 39-50). São Paulo, SP: IEE/PUCSP.

Severo, A. K. S., Dimenstein, M., Brito, M., Cabral, C., \& Alverga, A. R. (2007). A experiência de familiares no cuidado em saúde mental. Arquivos Brasileiros de Psicologia, 59(2), 143-155. Recuperado de http://pepsic.bvsalud.org/ scielo.php?script=sci_arttext\&pid=S1809-52672007000200005\&lng=pt\&tlng=p

Severo, A. K. S., Dimenstein, M., Brito, M., Cabral, C., \& Alverga, A. R. (2009). Família e práticas de cuidado em saúde mental. In M. Dimenstein (Org.), Produção do conhecimento, agenciamentos e implicações do fazer pesquisa em psicologia (pp. 69-80). Natal, RN: EDUFRN.

Simionato, M.A. W., \& Oliveira, R. G. (2003). Funções e transformações da família ao longo da história. In Anais do I Encontro Paranaense de Psicopedagogia (p. 57). Maringá, PR: Associação Brasileira de Psicopedagogia.

Soares, C. B., \& Munari, D. B. (2007). Considerações acerca da sobrecarga em familiares de pessoas com transtornos mentais. Ciência, Cuidado e Saúde, 6(3), 357-362. https://doi.org/10.4025/cienccuidsaude.v6i3.4024

Sousa, M. S., \& Baptista, M. N. (2008). Associações entre suporte familiar e saúde mental. Psicologia Argumento, 26(54), 207-215. Recuperado de http://www2.pucpr.br/reol/pb/index.php/pa?ddl=2495\&dd99=view\&dd98=pb

Szymanski, H. (2004). Práticas educativas familiares: a família como foco de atenção psicoeducacional. Estudos de Psicologia (Campinas), 21(2), 5-16. https://doi.org/10.1590/S0103-166X2004000200001

Tavares, C. M. M., \&Sobral,V.R. S. (2005). Avaliação das práticas de cuidar envolvendo arte noâmbito do Centro deAtenção Psicossocial (CAPS). Revista Mineira de Enfermagem, 9(2), 121-125. https://doi.org/S1415-27622005000200005

Vanderley, L. (2001) O vazio vivo. In A. Pitta (Org.), Reabilitação psicossocial no Brasil (pp. 63-71). São Paulo, SP: Hucitec. 
Vasconcelos, E. M. (2007). Dispositivos associativos de luta e empoderamento de usuários, familiares e trabalhadores em saúde mental no Brasil. Vivência, 32, 173-206.

Vasconcelos, E. M. (2004). Mundos paralelos, até quando? Os psicólogos e o campo da saúde mental pública no Brasil nas duas últimas décadas. Mnemosine, 1(0), 73-90. Recuperado de http://www.cliopsyche.uerj.br/livros/ cliol/mundosparalelosatequando.htm

\section{Raquel Souza Coelho}

Psicóloga, graduada em Psicologia pela Universidade Estadual da Paraíba (UEPB). Aluna recém-selecionada para o Mestrado em Serviço Social e Direitos Humanos na Universidade de Gotemburgo, Suécia.

E-mail: raquelsouzacoelho@gmail.com

\section{Thelma Maria Grisi Velôso}

Professora do Departamento de Psicologia da Universidade Estadual da Paraíba (UEPB) e Professora do Programa de Pós-graduação em Psicologia da Saúde (UEPB), Campina Grande - PB, Brasil.

E-mail: tgrisiveloso@gmail.com

\section{Sibelle Maria Martins de Barros}

Professora do Departamento de Psicologia da Universidade Estadual da Paraíba (UEPB), Campina Grande - PB, Brasil. E-mail: barros.sibelle@gmail.com

Endereço para envio de correspondência:

Rua Rodrigues Alves, 1979/104. Bairro Universitário. CEP 58429-145

Campina Grande - PB, Brasil.

Recebido 18/08/2015

Reformulação 08/03/2017

Aprovado 25/04/2017

Received $08 / 182016$

Reformulated $03 / 082016$

Approved 04/252017

Recebido 18/08/2015

Reformulado 08/03/2017

Aceptado 25/04/2017

Como citar: Coelho, R. S., Velôso, T. M. G., \& Barros, S. M. M. (2017). Oficinas com usuários de saúde mental: a família como tema de reflexão. Psicologia: Ciência e Profissão, 37(2), 489-499. https://doi.org/10.1590/1982-3703002612015

How to cite: Coelho, R. S., Velôso, T. M. G., \& Barros, S. M. M. (2017). Workshops with mental health users: the family as a theme for reflection. Psicologia: Ciência e Profissão, 37(2), 489-499. https://doi.org/10.1590/1982-3703002612015

Cómo citar: Coelho, R. S., Velôso, T. M. G., \& Barros, S. M. M. (2017). Talleres con usuarios de salud mental: la familia como tema de reflexión. Psicologia: Ciência e Profissão, 37(2), 489-499. https://doi.org/10.1590/1982-3703002612015 